\title{
PROJEÇÕES DE PRECIPITAÇÃO DOS MODELOS DO CMIP5 PARA O CENÁRIO RCP8.5 SOBRE O NORDESTE BRASILEIRO
}

\author{
Sullyandro Oliveira Guimarães ${ }^{1,}$, Alexandre Araújo Costa ${ }^{1}$, Domingo Cassain Sales ${ }^{2}$, \\ Francisco das Chagas Vasconcelos Júnior ${ }^{3}$ \\ ${ }^{1}$ Universidade Estadual do Ceará - UECE (sullyandro@gmail.com) \\ ${ }^{2}$ Fundação Cearense de Meteorologia e Recursos Hídricos \\ ${ }^{3}$ Universidade de São Paulo - IAG - USP \\ *sullyandro@gmail.com
}

\section{RESUMO}

A precipitação é uma variável de importância destacada sobre o Nordeste Brasileiro (NEB), pela avaliação dos recursos hídricos, eventos extremos, e etc. Nesse sentido se fez a análise da precipitação modelada para o clima presente (1985-2005), e clima futuro (20792099) projetado em um cenário de altas emissões de gases de efeito estufa.

\section{ABSTRACT}

Precipitation is one important variable highlighted over the Brazilian Northeast (NEB), to assessment of water resources, extreme events, and etc. In this sense the analysis is made of the precipitation modeled for the present climate (1985-2005), and future climate (2079-2099) projected in a scenario of high emissions of greenhouse gases.

\section{INTRODUÇÃO}

O Nordeste Brasileiro (NEB) é uma região de grande variabilidade climática, possuindo boa parte do semiárido do país, e sofre com alternações irregulares de anos extremos (secos ou chuvosos) conferindo assim considerável sensibilidade climática. Com as mudanças que vem ocorrendo desde a introdução da cultura de utilização de combustíveis fósseis, o clima tem sido um fator preocupante diante da globalização. Cada vez mais estão sendo feitos estudos dos impactos da ação antrópica sobre o sistema climático, e assim atribuir as causas das mudanças que já são notadas. Nesse sentido o IPCC (Intergovernmental Panel on Climate Change) foi criado e vem trazendo melhorias no entendimento e prevenção de mudanças climáticas. Por sua carência de estudos e necessidade de melhores abordagens sobre como o NEB responderá as mudanças que podem vir a ocorrer, são abordadas as análises e projeções das simulações climáticas dos Modelos 
de Circulação Geral do CMIP5 (Coupled Model Intercomparison Project - Phase 5). O cenário de emissões de gases de efeito estufa, que projeta forçamento radiativo no final no século 21 de 8,5 W/m², chamado RCP8.5, foi então abordado para a análise. (TAYLOR et al., 2008; IPCC et al., 2007)

\section{MATERIAIS E MÉTODOS}

$\mathrm{Na}$ avaliação do desempenho das simulações do clima presente são feitas abordagens com índices estatísticos (correlação, viés, etc.), comparando a Média-Modelos (média dos dados simulados pelos modelos CESM1-CAM5, CESM1-BCG, CCSM4, HadGEM2-AO, HadGEM2-CC, HadGEM2-ES, NorESM1-M, NorESM1-ME, GFDLESM2G, BNU-ESM, CanESM2, MIROC-ESM, MIROC-ESM-CHEM) com o dado observado CFSR (Climate Forecast System Reanalysis). Após as análises de validação dos modelos, são analisadas as projeções de mudanças climáticas para o cenário RCP8.5 comparado com as simulações do período histórico. As áreas de estudo consistem de três subdomínios do NEB, NNEB (44W-36W, 8S-2S), ENEB (37W-34W, 10S-4S), SNEB (46W-38W, 16S-8S), como destacado nas figuras das médias sazonais (Figura 2).

\section{RESULTADOS E DISCUSSÃO}

Na avaliação do clima presente simulado pelos modelos, têm-se que a MédiaModelos apresenta melhores resultados de correlação espacial da climatologia para as estações secas sobre o ENEB e SNEB, seguindo ainda da boa representação climatológica da média mensal para as três regiões do estudo, com o NNEB divergindo quanto a correlação espacial no período seco.

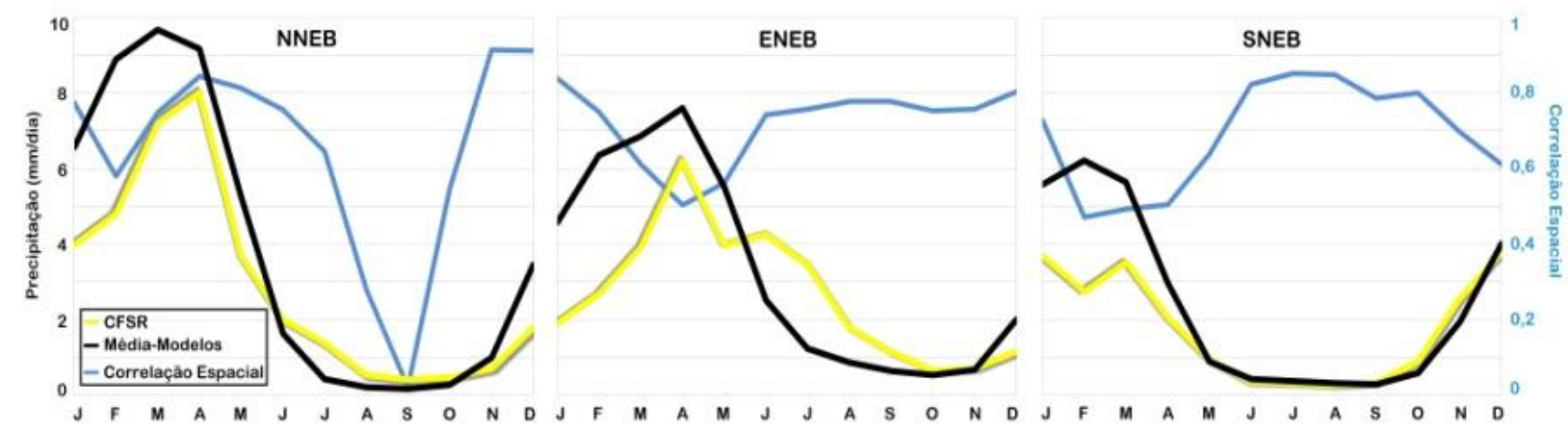

Figura 1 - Climatologias da Média-Modelos e CFSR. 

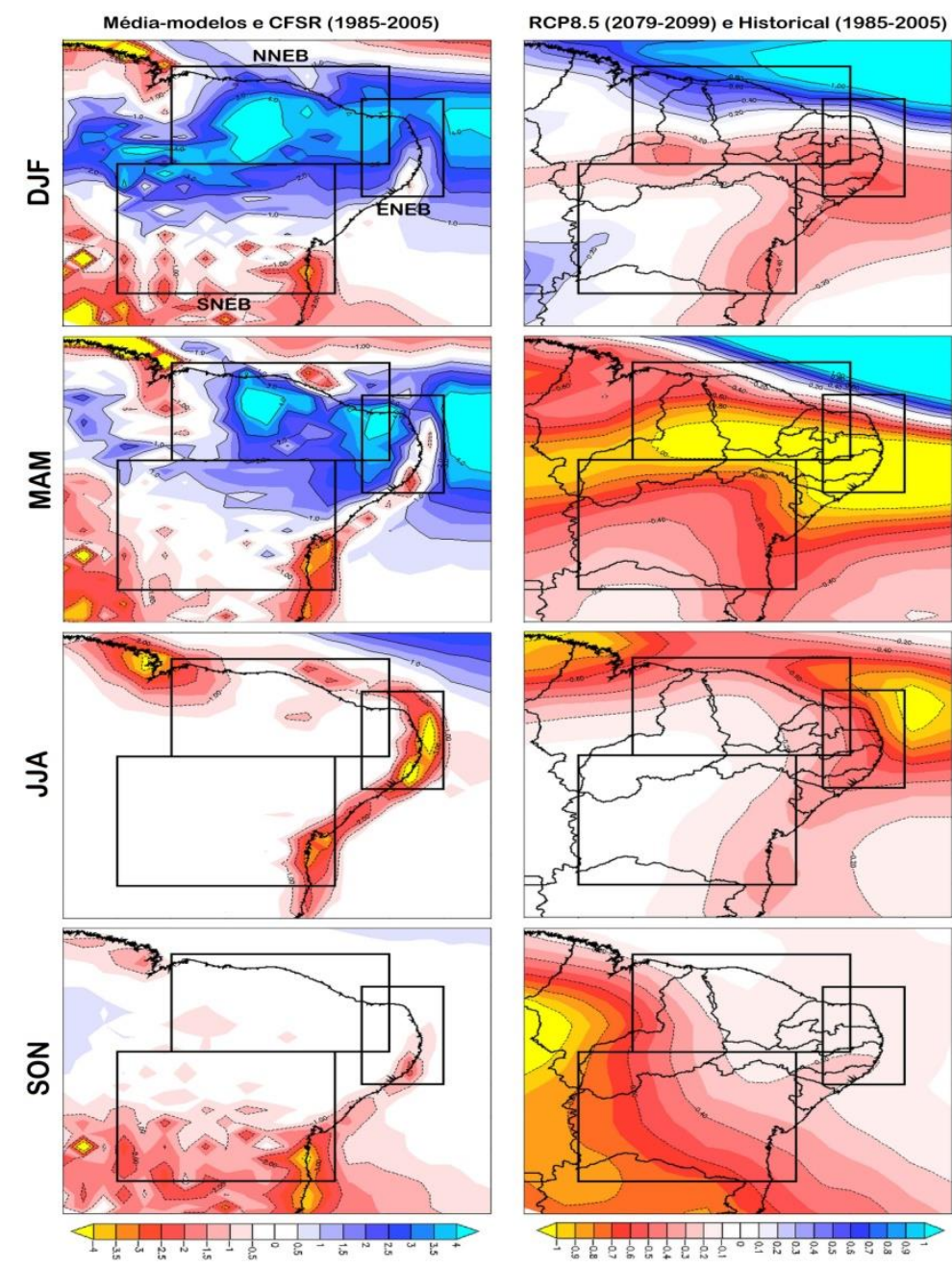

Figura 2 - Mapas sazonais de diferença para o presente e projeção.

Em JJA (junho, julho e agosto) o ENEB segue com viés seco (principalmente no litoral), diminuindo em SON (setembro, outubro e novembro). Já SNEB tem pouco viés, com maiores erros na estação chuvosa das simulações do presente.

As projeções para o RCP8.5 apontam pequena redução climatológica, com maiores mudanças espaciais sazonais como vista na Figura 2.

\section{CONCLUSÕES}

A precipitação sobre o NEB já tem sua importância potencializada pelo próprio clima e demais características regionais, tornando os resultados das projeções relevantes, que mostram indícios de mudanças sobre toda a região analisada, como redução da precipitação em grandes áreas, seguindo um viés negativo climatológico futuro no cenário de emissões de GEEs RCP8.5. 


\section{AGRADECIMENTOS}

A FUNCAP que financiou esse estudo através da concessão de bolsa de mestrado ao autor (Projeto ACNE - CAPES/FUNCAP Áreas Estratégicas, Edital 03/2013, Processo AE10052-000110100/11), e através do suporte logístico para execução dos projetos de pesquisa que contribuíram com a elaboração do trabalho.

\section{BIBLIOGRAFIA}

IPCC, Summary for Policymakers. In: Climate Change 2007: The Physical Science Basis. Contribution of Working Group I to the Fourth Assessment Report of the Intergovernmental Panel on Climate Change [Solomon, S., D. Qin, M. Manning, Z. Chen, M. Marquis, K.B. Averyt, M.Tignor and H.L. Miller (eds.)]. Cambridge University Press, Cambridge, United Kingdom and New York, NY, USA. 2007.

TAYLOR, K. E.; STOUFFER, R. J.; MEEHL, G. A. A Summary of the CMIP5 Experiment Design. 31 de Dezembro de 2008. 